\title{
Aufforderung betreffend Beobachtungen der glänzenden Himmelserscheinungen, welche seit dem Sommer 1885 öfter in Mittel-Europa gesehen worden sind.
}

Seit dem Sommer des Jahres 1885 sind in MittelEuropa an verschiedenen Orten höchst merkwürdige glänzende Erscheinungen am Morgen- und Abendhimmel gesehen worden. Obwohl bisher nicht bekannt geworden ist, dass die Erscheinungen auch in anderen Erdtheilen gesehen worden sind, so ist es doch sehr wahrscheinlich, dass sie uber die ganze Erde verbreitet sind. Wenn dieselben in anderen Welttheilen bisher nicht aufgefallen sind, so mag dies hauptsächlich darin liegen, dass das Phänomen, wenn es in seinem grössten Glanze steht, nahe am Horizonte sich befindet, weshalb es, da der Horizont innerhalb bewohnter Orte mehr oder weniger verdeckt ist, meist nur schwer wahrgenommen werden kann.

Die Erscheinung verdient an sich das lebhafteste Interesse, ausserdem zeigen sich an derselben besondere Eigenthümlichkeiten, welche es wünschenswerth erscheinen lassen, dass dieselbe auch in anderen Erdtheilen näher verfolgt wird. Diese Eigenthümlichkeiten bestehen darin, dass das Phänomen in Mittel-Europa bis jetzt nur um die Zeit des Sommer-Solstitiums beobachtet worden ist. Die Erscheinung wurde zuerst am 23. Juni i 88.5 bemerkt, und sie hielt mit einigen Unterbrechungen bis zum 27. Juli an. In derr gegenwärtigen Jahre wurde sie zuerst am 28. Mai gesehen, und ist seitdem ebenfalls mit Unterbrechungen öfter wahrgenommen worden. In dem Folgenden gebe ich eine nähere Beschreibung des Phänomens, wie ich es. am 19. Juli 1885 beobachtet habe.

Die Sonne ging am rg. Juli um $8^{\mathrm{h}} 9^{\mathrm{m}}$ bei ganz klarem Himmel unter. $U m 8^{\mathrm{h}} 24^{\mathrm{m}}$ erschienen an den verschiedensten Stellen des Himmels vereinzelte, sehr zarte, weisse Streifen, ähnlich sehr leichtem Cirrusgewölk. Mit weiter sinkender Sonne wurde die Sichtbarkeit dieser Streifen auffallender. Während sie aber im Allgemeinen an Flächenausdehnung zunahmen, so dass nach einiger Zeit die ganze Himmelsfläche damit bedeckt erschien, machte sich an dem der Sonne gegenüberliegenden Theile des Himmels, im Südosten, bereits eine Auslöschung bemerkbar. Diese Auslöschung dehnte sich langsam nach Nordwesten

Sternwarte Berlin, I 886 Juni. hin aus, und zwar war dieselbe so vollkommen, dass nichts als der tiefblaue Himmel bemerkt wurde an Stellen, an welchen vorher die weissen Wolken gesehen worden waren. Mit dem weiteren Zurückziehen der Erscheinung nach Nordwesten hin hatte dieselbe ein immer lebhafteres Licht gegen die Umgebung erhalten. $\mathrm{Zu}$ der Zeit, als die obere Grenze des Phänomens im Nordwesten etwa I $^{\circ}$ hoch war, gegen $9^{\mathrm{h}} 40^{\mathrm{m}}$, war der Lichtunterschied zwischen demselben und dem übrigen Himmel ungefähr so gross, wie der Lichtunterschied der Flächę des Mondes gegen den Himmel zu der Zeit, wenn die Sonne im Horizonte steht und wenn die Höhe des Mondes mehr als $10^{\circ}$ beträgt. In der Höhe von $8^{\circ}$ bis $12^{\circ}$ war das Licht der Erscheinung ein silberglänzendes Weiss; etwas tiefer wurde die Farbe goldglänzend, in grösster Nähe des Horizontes jedoch schmutzig gelb.

Aus den an diesem und an anderen Abenden, an welchen die Erscheinung ganz ähnlich auftrat, angestellten Beobachtungen uber die Winkelhöhe des nach Nordwesten hin vorrückenden Schattens der Erde ergiebt sich mit hoher Wahrscheinlichkeit, dass das Phänomen durch einen in den obersten Schichten der Atmosphäre enthaltenen fremdartigen, sehr feinen Stoff, welcher durch die Sonne beleuchtet wird, zu Stande kommt. Die lineare Höhe der oberen Grenze der Materie über der Erdoberfläche beträgt etwa 50 Kilometer, eine Höhe, in welcher die Dichtigkeit der Luft verschwindend klein ist. Auffallend und höchst merkwürdig ist es aber, dass die Erscheinung bis jetzt nur in den Sommermonaten gesehen worden ist.

Es ist sehr wünschenswerth zu einer vollständigen Discussion, dass diese Erscheinung, über welche bereits eine kleine Arbeit*) von mir vorliegt, auch in anderen Erdtheilen, besonders in südlichen, beobachtet wird. Ich bitte daher um Mittheilung von Beobachtungen; jede, auch die kleinste Notiz, wird mit Dank entgegengenommen werden.

*) Meteor. Zeitschrift r886 p. 8.

\section{Aufforderung betreffend Beobachtungen des Cometen 1880 II (Schaeberle).}

Die Herren Astronomen, welche obengenannten Cometen beobachtet und die Beobachtungen noch nicht veröfentlicht haben, werden ergebenst ersucht, dieselben sammt den dabei verwendeten Vergleichsternen mir mitzutheilen.

Prag 1886 Juni 29.

Dr. B. Schwarz, Assistent der Śternwarte in Prag.

\section{In h a l t:}

Zu Nr. 2737. O. Lohse Ueber Stellarphotographie: I. - R. Lehmann-Fïhés. Bemerkung über Jacobi’s Vorlesungen über Dynamik. I3. $O$. Fesse. Aufforderung betreffend Beobachtungen der glänzenden Himmelserscheinungen, welche seit dem Sommer 1885 öfter in Mittel-Europa gesehen worden sind. 15. - B. Schwarz. Aufforderung betreffend Beobachtungen des Cometen 1880 II (Schaeberle). 15. 